\title{
Operations Management at the Service of Health Care Management: Example of a Proposal for Action Research to Plan and Schedule Health Resources in Scenarios Derived from the COVID-19 Outbreak
}

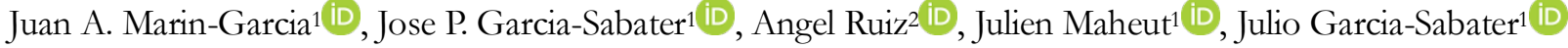 \\ ${ }^{1}$ ROGLE. Dpto. de Organización de Empresas. Universitat Politècnica de València (Spain) \\ ${ }^{2}$ Département d'opérations et systèmes de décision, FS A ULaval (Canada) \\ jamarin@omp.upv.es,jpgarcia@omp.upv.es, Angel.Ruiz@osd.ulaval.ca, juma2@upvnet.upv.es, \\ jugarsa@omp.upv.es
}

\section{Abstract:}

Purpose: With this work, we intend to promote research on the application of Operations Management tools in order to assist with decision-making in health crisis situations. During the first six weeks of the COVID-19 crisis in Spain, we have contacted a large number of hospital and health department managers in the Valencian Community and other regions of Spain. The result is that very few, at least when contact was made and at the time of writing this article, had consulted staff members in the Operations Management area for advice on this situation, and they are quite reluctant to do so. This is in spite of the fact that some medical sources also consider this crisis to be one of resources, not merely a medical crisis. Our opinion is that Operations Management can make a useful and valuable contribution to anticipate and improve the management of scarce resources, even in times of crisis. If those responsible for public health or heads of hospitals do not see this usefulness, then there is a huge gap between research and practice in Operations Management and what is transmitted to the healthcare sector. Our aim is to help reduce this gap.

Design/methodology/approach: In the first part of the article, we will justify that this crisis, besides being a medical crisis, is also a crisis in terms of resources. We will briefly review some of the Operations Management tools that we believe are appropriate for managing this crisis. We will focus on those that we will illus trate in the second part of the article as a practical example of the action research protocol (only the action planning phase), in which we are currently involved.

Findings: Due to the peculiarities of the COVID-19 epidemic, it is reasonable to think that the evolution and duration of each outbreak, and the way it is dealt with, will be different in each hospital and/or each health department. Anticipating the number of patients who will require care and forecasting the consumption of resources over time is complex, due to the long and variable incubation times and the uncontrolled evolution of the treatments needed by each patient. Furthermore, since the evolution of new patient admissions is not homogeneous, the forecasting of requirements is difficult. Providing real-time support and detecting with a certain degree of anticipation the potential levels of demand for health care will enable hospitals to define what stages of the contingency plan to apply and how to (re)assign the available resources in the most efficient way possible.

Research limitations/implications: Hardly any current data are available, not only publicly, but also through public health ministries and managers; those that are available are not very reliable and come from studies with non-representative samples. For this reason, all forecasts must be taken with a note of caution, 
and in particular, designing review mechanisms every time a new set of updated reliable data becomes available (something that occurs on a weekly basis).

Originality/value: In this work, we will show an example of a proposal for the practical application of Operations Management tools. Our proposal may be useful to hospital managers and public administrators in the healthcare sector (regional ministries or their equivalents). Each health department, hospital or hospital group will generate the aggregate data that facilitate the calculation of needs as input parameters for the model (available and occupied beds, daily admissions, mean lengths of stay in each healing phase and the percent of patients who evolve from one stage to another in the progression of the disease/healing process) and will be able to analyze how the system responds and evaluate different strategies or mitigating actions. These tools have been shown to be useful and reliable in manufacturing and service contexts that show a strong seasonal demand (both occasional and recurring) requiring a great deal of resources. We believe these situations are analogous to those faced by hospitals and the healthcare system in an epidemic like COVID19. With them, we could facilitate the aggregate planning of resources for hospital administrators in order to provide them operational support during the COVID-19 contingency plan. However, the array of useful tools for this crisis is not limited to those that we will illustrate. Our intent is to encourage the Operations Management academic community to demonstrate how they contribute to the service of society in this COVID-19 epidemic, providing knowledge that can be extrapolated to other similar situations in the future that we may be unfortunate enough to experience.

Keywords: Action research, COVID-19, discrete event simulation, theory of constraints, operations management, healthcare

\section{To cite this article:}

Marin-Garcia, J.A., Garcia-Sabater, J.P., Ruiz, A., Maheut, J., \& Garcia-Sabater, J. (2019). Operations Management at the Service of Health Management: Example of a Proposal for Action Research to Plan and Schedule Health Resources in Scenarios Derived from the COVID-19 Outbreak. Journal of Industrial Engineering and Management, 13(2), 213-227. https://doi.org/10.3926/jiem.3190

\section{Introduction}

The current health crisis is caused by the infectious disease COVID-19, produced by a human $\mathrm{CoV}(\mathrm{HCoV})$ from the $\beta$ corona virus subgroup, SARS-CoV2, which had not been detected in humans until late 2019 (Ferguson et al., 2020). Through close human contact (direct and indirect), the SARS-CoV2 virus triggers the transmission of a respiratory disease, COVID-19, that is similar to the flu (influenza), with various symptoms (cough, fever, etc.), which in severe cases cause epidemics and lower respiratory infections with different levels of clinical severity (pneumonia, with varying levels of severity), and a variable mortality rate (1-35\%), according to several different determining factors (Aylward \& Liang, 2020; Bhatraju et al., 2020; European Centre for Disease Prevention and Control, 2020; Ferguson et al., 2020).

There is little doubt that the COVID-19 epidemic is a medical crisis that is putting the capacity of the healthcare system to the test, in order to, among many other things, develop faster and more reliable diagnostic tests, establish better patient-care protocols, determine how the virus behaves and is dispersed, and develop possible vaccines or treatments. But this crisis is also one of resources. Staff members, as well as beds, protective equipment and available test units are scarce resources at certain moments and in certain places, and can at the same time (or at different times) be a resource with certain abundance in others. To give an example, in Spain, during the first six weeks of the lockdown, the shortage of COVID-19 diagnostic tests and protective equipment was the dominant situation at all health centers. However, in areas such as the province of Valencia, there was no shortage of either beds or healthcare workers. This situation was completely different from that in Madrid, Barcelona, provinces in the center of the 
country and even some health departments in the province of Alicante (within the same geographic region as the province of Valencia).

Three preliminary phases are proposed in this work (definition of the problem, identification of the relevance of the topic and action planning) for an action research (Erro-Garcés \& Alfaro-Tanco, 2020; Marin-Garcia et al., 2018) that will be carried out over the next few months. Within it, the development of a tool is proposed to support decisionmaking based on possible resource consumption scenarios in the health services, in light of an uncontrolled COVID19 pandemic. For the development of this tool, first of all, the patient trajectories have been identified that represent the sequence of processes or stages through which they pass from the time they arrive at the hospital until they are dismissed. A parametrization of times and probabilities of transition between the stages will then be carried out. Based on these data, and taking into consideration the capacity of hospital resources, it is possible to simulate by means of discrete events the evolution of the availability/saturation of the resources day by day for an arbitrary horizon (for example, 8 weeks), which will facilitate the planning of resources and personnel (rostering) in a context of limited resources. In addition, the simulation can be extended to generate scenarios that permit the planning of capacities in a context of network-based execution (increase, acquisition or the making available of resources). We intend to synchronously simulate several models, each of which represents a healthcare establishment that belongs to the same service network (health department). In this way, we can explore the impact of different collaborative strategies on the overall performance of the healthcare system.

Furthermore, although little evidence has been collected and evaluated concerning the impact of COVID-19 on the regular healthcare activities, a high volume of elective procedures and chronic treatments has been reprogrammed or just cancelled due to the outbreak. If the consequences for the population are difficult to assess, this situation may have had a fatal impact on rural hospitals that fire workers or shout their doors in response to COVID-19(Paavola, 2020). Anticipating COVID-19's needs will certainly allow decision makers to elaborate plans to synchronize COVID19 to non-COVID-19 resources and activities in an attempt to mitigate the effects on the population.

With the support of a simulation based on discrete events, it is possible to analyze, for a particular hospital, the effectiveness and efficiency of the service (according to the established objectives) for a certain strategy of internal resource management. The tool can be used in the scope of the healthcare system in general, or one of its departments, or to make decisions related to a specific hospital, over the short-term (with the available resources). But at the same time, the simulation can be used to anticipate future scenarios and manage the acquisition/redistribution of resources to deal with the evolution of healthcare once the highest peaks or the initial transition period of the propagation of the disease have passed. If we evaluate and synchronously simulate several health centers, different coordination and cooperative strategies can be considered (both in terms of resources and the transfer/referral of patients). A multi-hospital simulation would permit anticipating the peaks of healthcare demand and evaluating how to improve the distribution among the centers on the network, by forecasting the need for resources, in terms of both equipment (beds, portable respirators, etc.) and healthcare personnel (medical personnel, nursing staff, hospital attendants and/or cleaning and security staff) far enough in advance to organize work teams (particularly staff and shifts).

The starting point for adapting the tool stems from the know-how (algorithms and models) in industrial settings and services from the ROGLE group. The group has cooperated in problem solving in settings with variable demand (Saez-Mas et al., 2020) and in the logistical response in medical crisis situations (Wanying et al., 2016). During the second week of the Spanish lockdown, the group had a design/functional draft that was backed by a validated methodology (Saez-Mas et al., 2018). The models will be parameterized to fit the available data and the peculiarities of the protocols and situations experienced in each hospital context. In this way, they can be easily adapted as other data or medical protocols are implemented.

Our proposal could be useful for hospital administrators (or directors of clinical departments who are responsible for managing resources in relation to COVID-19 or any other infection) and public managers in the field of healthcare (regional ministries or their equivalents). Each health department, hospital or hospital group will generate the aggregate data that facilitate the calculation of needs as input parameters for the model (available and occupied beds, daily admissions, mean lengths of stay in each healing phase and the percent of patients who evolve from one stage 
to another throughout the progression of the disease/healing process) and will analyze how the system responds and evaluate different strategies or mitigating actions.

\section{The COVID-19 crisis from an Operations Management Perspective}

At this time, the clustering of different patient types, the stages they will pass through during the course of the disease and the time each stage lasts can be considered rather inconclusive. The diagram and data in Figure 1 have been taken from different sources (Aylward \& Liang, 2020; Bhatraju et al., 2020; European center for disease prevention and control, 2020; European Centre for Disease Prevention and Control, 2020; Ferguson et al., 2020; Manninen, 2020; National Vital Statistics System, 2020; Zhou et al., 2020). In theory, we can consider them to be the best approximation available during the first six weeks of the lockdown in Spain, until more up-to-date data are available to replace these estimates.

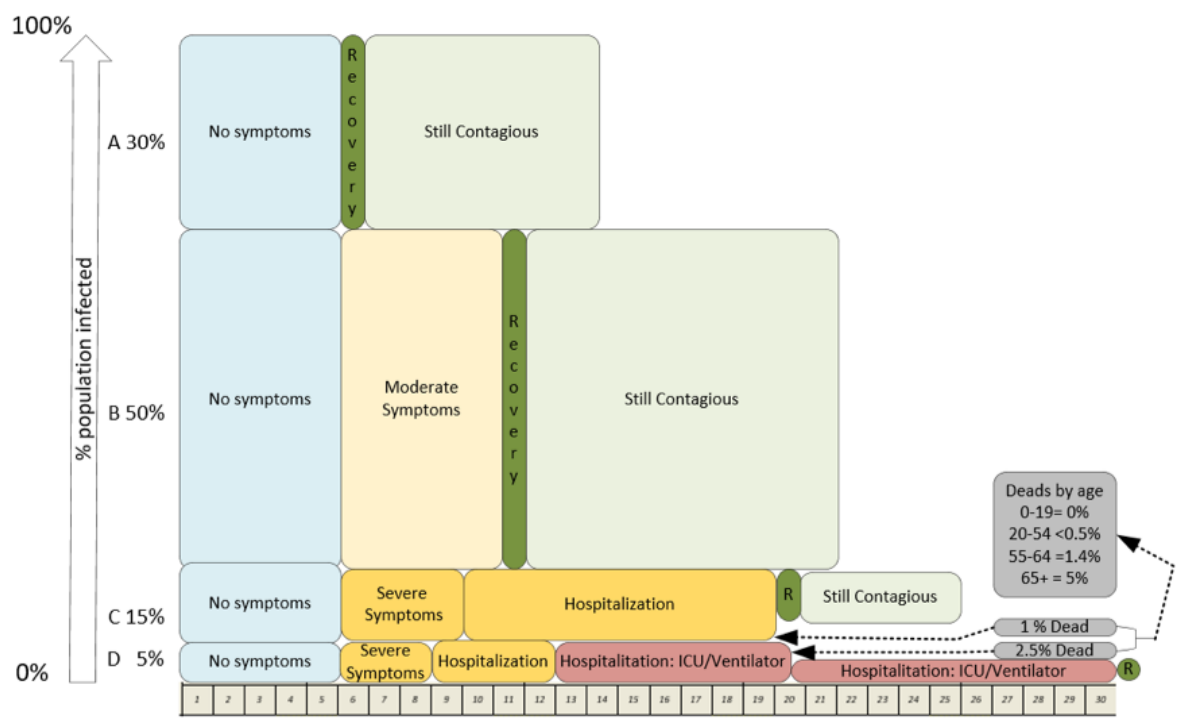

Figure 1. Typical progress of a COVID-19 patient

If the scenario shown in Figure 1 is correct, these data allow us to approximate the evolution of the disease, based on the reliable data available. These data will vary greatly from one country to another. For example, in Spain, the only reliable data as of today (six weeks after the lockdown) are the number of hospital admissions (and deaths and recoveries of hospitalized patients). This is because the diagnostic tests in Spain are not being administered to representative samples of the population, rather fundamentally to patients with severe symptoms who seek assistance from hospital emergency rooms. There are different groups of researchers who are making predictions of how the disease will evolve, based on mathematical models (Martín-barroso et al., 2020; Salje et al., 2020; Verity et al., 2020). But until there are randomized samples that allow us to know with any guarantees the evolution of the disease, simple estimates can also be used, based on known data in a specific context and a little more creative approach to the problem. For example, we know for sure that in the city of Valencia and the neighboring towns, there are 5 health departments that provide services to a population of 1,588,000 inhabitants, and there are 2,982 beds available in their hospitals (Generalitat Valenciana, 2018). The data in Figure 1 indicate that $20 \%$ of the population will require hospitalization during the pandemic and the average hospital stay is two weeks. Therefore, once the entire population has been infected, around 635,200 hospitalized_patient weeks $(1,588,000 * 20 \%$ patients_hospitalized $* 2$ weeks) will have been needed. However, if all the beds in the health area corresponding to the public system in the city of Valencia had been occupied by patients during the first six weeks of the pandemic, 17,892 hospitalized_patient weeks would have occurred (2,986 beds available for hospitalization * 6 weeks). Therefore, since we know that the Valencian healthcare system did not collapse during the first six weeks of the pandemic (Sanchis \& Martínez, 2020), we can estimate that, assuming that the data from Figure 1 are accurate, there cannot have been more than 3\% $(17,892 / 635,200)$ of the population infected in the area of the city of Valencia. These data seem to agree with the 
predictions made for Spain (Martín-barroso et al., 2020) and those representing a geographic area with a low pandemic intensity in France (Salje et al., 2020).

If we consider that the real current prevalence is very low, it is anticipated that SARS-CoV2 will continue to reappear in a stochastic manner that is thus unpredictable (European center for disease prevention and control, 2020). Due to the peculiarities of the COVID-19 disease, it is reasonable to think that the evolution and duration of each outbreak, and the way it is dealt with, will be different for each hospital and each health department. For this reason, health departments must have a contingency plan that allows them to anticipate the number of patients who will require care and their distribution over time (Fernandes et al., 2020). However, these decisions are difficult, due to the long and variable incubation times and subsequent treatment, as well as the possible non-homogeneous evolution of new patients (Aylward \& Liang, 2020; European center for disease prevention and control, 2020; Hellewell et al., 2020; Sodhi \& Tang, 2011; Zhang et al., 2020).

Each administrative body in the health department must decide what resources to plan and which to leave alone when the virus expands in their area of influence. These resources can range from the staff members themselves (medical personnel, nursing staff, nursing assistants, hospital attendants, cleaning and security staff and volunteers), the facilities (beds in general hospital wards, beds in intensive care units, beds in respiratory intensive care units) and equipment subject to inventory (electrocardiograms, ventilators, non-invasive mechanical ventilation equipment, etc.), to pharmacy supplies (drugs and medications), personal protective equipment (airway protectors, facial protectors, hand protectors, body protectors, eye protectors, etc.) and cleaning material. For any professional, in particular, healthcare professionals, in these settings it is common for decision-making to be difficult, due to the complex projection of the current situation and the unpredictable situation of incoming patients over the following days. In addition, a considerable percentage of patients admitted on a given day will remain in the hospital weeks later, continuing to require resources. Finally, the requirements vary a great deal, according to the patient's current stage (Ruan et al., 2020).

However, using quantitative tools, it is possible to dimension the necessary resources in environments characterized by high levels of uncertainty in terms of data (Mula et al., 2007). The continuous growth in the complexity of hospital management makes it difficult to efficiently coordinate services in their different stages, using traditional approaches based on Material Requirement Planning (MRP) and production finite-capacity programming tools, and thus it is necessary to develop new procedures to achieve this goal (Arias Aranda \& Minguela Rata, 2018). The extreme variability of the resource demand which characterizes the pandemic is not common in the hospital sector, but it has been previously considered by the literature (Bedoya-Valencia \& Kirac, 2016; Brailsford \& Vissers, 2011; Demir et al., 2017; Hu et al., 2018; Paul et al., 2010; Safdar et al., 2016).

In this sense, in settings characterized by a great need for coordination of decisions among the members of the healthcare system and by high levels of uncertainty and complexity, the forecast of the demand can be considered to reduce the uncertainty (generation of possible scenarios), as well as resource planning (Molina-Pariente et al., 2015) taking into account Theory Of Constraints, would facilitate complex decision-making in each scenario (Gupta \& Andersen, 2018; Lin et al., 2004; Miclo et al., 2019; Wee et al., 2016).

The current health management systems have evolved towards a concept that is similar to that of a chain or network (Bae et al., 2019; Choi et al., 2001; Pitt et al., 2016; Postacchini et al., 2016; Sholihah et al., 2018; Squires et al., 2016), in which its links (made up by different levels of care, but also different levels of severity of patient condition) (MarinGarcia et al., 2019; Vidal-Carreras et al., 2015) have the function of managing resources and providing services in the most efficient way possible (Chase et al., 2004).

However, for the management of the chain, a high level of predictability, stability and leveling of demand and stability of the production processes dedicated to supply is required (Doolen \& Hacker, 2005). In some cases, such as the current COVID-19 crisis, this stability is not possible. The variations in the patterns of healthcare demand make resource planning more unstable. Furthermore, as the complexity of the healthcare chain/network increases, the need of supply chain coordination grows. Moreover, the instability is greater as we regress more to upstream steps on the chain, generating situations that can result in the so-called "bullwhip" effect, which is widely referred to in the 
literature (Forrester, 1997; Frazee \& Standridge, 2016; Geary et al., 2006; Moktadir et al., 2018; Sodhi \& Tang, 2011; Wee et al., 2016).

In the context of manufacturing or services, there are numerous studies (Bayou \& De Korvin, 2008) that show that the management of multi-stage chains or networks is complex on all levels, and this complexity increases as we descend to the more operational level of service programming (Cooney, 2002). To reduce this complexity, for over 40 years now, focuses based on MRP systems have been common (Miclo et al., 2019). This approach makes it possible to coordinate the different links on these chains and apply finite capacity programming techniques within each of them (Benton \& Shin, 1998; Berger, 1987). We can also highlight some experiences based on the paradigm of Theory Of Constraints (Alzubi et al., 2019; Gonzalez-R et al., 2010; Gupta \& Andersen, 2018; Gupta \& Snyder, 2009; PérezCampdesuñer et al., 2017). However, in spite of the efforts toward implementing all these techniques, it is still common for uncontrolled resource management (Eroglu \& Hofer, 2011), difficulties in patient or supply flows (Jina et al., 1997) or reprogramming and frequent changes to occur (Aytug et al., 2005). We believe that part of this previous knowledge can be adapted and used in the area of hospital management. For example, concepts, such as "heijunka" (smoothing or leveling of production/service) (Ohno, 1988; Shingo \& Dillon, 1989; van Donk, 2010), cyclical schedules that match leveled demands (Packowski, 2013), adjustments through the reprogramming of the number of healthcare workers needed to adapt to the changing demand (Monden, 2011), or staff versatility (Åhlström, 1998; Bean et al., 2019; Cho et al., 2019; Goddard, 1982; Thürer et al., 2015), have a more direct application to health services.

Beyond the material resources, the health services rely on the continuous presence of a team of people with different knowledge and training. The creation of work and break schedules is, as a result, a critical factor in hospital capacity management. Even though tools exist that assist those responsible for scheduling professionals, these tools are not adapted to the working conditions associated with crisis situations like that caused by COVID-19. In fact, the uncertainty of the crisis situation makes it more appropriate to start to use procedures that study plausible scenarios and propose viable alternatives. This is particularly true taking into account that, unfortunately, there is a high rate of temporary leaves by medical staff, and therefore the team membership may vary. By considering the integration of the different phases involved in caring for COVID-19 patients, coordination is required between the time needed to provide care in the different stages through which the patient may pass, as well as the definition of sequences and their timing, in order to minimize the misalignments between said stages as much as possible (Maheut et al., 2012). The intent is to contribute to creating a continuous flow throughout the patient care process.

In summary, we suggest that it would be interesting to develop integrated medical resource planning tools adapted to the context of uncertainty that characterizes a crisis such as that generated by COVID-19. To do this, simulation can be used to estimate the dynamic of the needs with a horizon of 6-8 weeks and, based on them, use optimization models to plan resources. A second group of tools could be designed to modify the plans in quasi-real time (with a horizon of only a few days), according to the real situation that is presented when the data are updated.

\section{Practical Example of Action Planning}

\subsection{Research Objectives}

We propose the modeling and simulation of processes by discrete events, using a combination of patient flow, resources and information. With it, we intend to anticipate the resource and personnel needs required to provide service, from the time the expansion of the virus begins until it disappears. The resources that we will consider range from personnel (doctors, nurses, nursing assistants, hospital attendants, cleaning and security staff and volunteers) to equipment subject to inventory (beds, intensive care units, respiratory intensive care units, non-invasive mechanical ventilation equipment, invasive mechanical ventilation equipment), and may extend if necessary to personal protective equipment (masks, gloves, goggles, robes, etc.), cleaning material and medications.

To achieve this, we will break down the overall objective into these specific objectives:

(1) Diagnosis and description of the main problems related to the programming of hospital resources during the COVID-19 crisis. 
(2) Identification of the processes/stages from the time the COVID-19 patient arrives at the hospital until his/her dismissal.

(3) Development of theoretical models that adequately represent the programming of resources in this type of settings.

(4) Parameterization of lengths of stay and probabilities of patient evolution.

(5) Development of simulation models based on discrete events. These models will represent the evolution of the availability/saturation of the resources day by day, over a horizon of 4-8 weeks. They will take into account the need for coordination on different levels and the possibility of reprogramming/reassigning resources or referring patients in this type of settings as necessary.

(6) Programming (scheduling and rostering) in a context of limited hospital resources.

(7) Simulation over a horizon of 3-4 months, in order to generate scenarios that permit capacity planning in a context in which the possibility exists to acquire or increase resources.

(8) Design of tools that permit the hospitals in question to respond to their needs in terms of resource programming during each of the stages, abiding by the present restrictions.

(9) Integrating, as much as possible, the tools designed with the hospital information systems (HIS), by means of protocol HL7 (Aijing \& Jin, 2015; Ileri, 2016; Kiourtis, Mavrogiorgou, et al., 2019; Kiourtis, Nifakos, et al., 2019).

The basic hypotheses on which the action research is based are as follows:

(1) Problems that arise when programming resources on healthcare chains in COVID-19 contexts may be modeled.

(2) The resulting models can be optimally resolved by means of standard algorithms or those developed ad hoc, using commercial optimization or simulation software for simplified and small problems.

(3) The results of the previous point can be used as a starting point for developing efficient procedures to solve more complex problems in hospital management. These procedures will be based on heuristic and metaheuristic algorithms and will be validated in uncertain, multi-objective environments through simulation.

(4) The creation of a contingency plan (protocols) based on scenarios improves the coordination and integration of health services.

(5) The anticipation of demand peaks a few days before they occur permits a better application of the contingency plan, increases the capacity for managing resources and improves the healthcare capacity in crisis situations.

In addition, it is necessary to identify or design, in conjunction with the stake holders, the Key Performance Indicators (KPI) that make it possible to evaluate alternative decisions. Indicators such as the number of deaths, number of days that the hospital (health area) exceeds nominal capacity (patients per doctor and shift) and percentage of occupancy in each area of the hospital would probably be useful, although other indicators may be added to this list.

\subsection{Contribution}

The tools that we will propose are a customization for the healthcare sector and specific hospitals of the tools designed and tested in other organizational contexts (manufacturing and services). In these contexts, it has been demonstrated that these tools provide useful, reliable and proven solutions for situations of sharp seasonal demand (both occasional and recurring) that require a large amount of resources. We believe these situations are analogous to those faced by hospitals and the healthcare system in an epidemic like COVID-19.

In this way, we will provide hospital administrators with a package of tools for aggregate resource planning, in order to provide them with operational support during the COVID-19 contingency plan. These tools will be focused on: the modeling of demand through the analysis of service trajectories (demand prediction scenarios, transition scenarios); linear programming based on scenarios with deterministic data (demand prediction scenarios, transition scenarios), where each hospital has certain characteristics and different patients; and programming with nondeterminist data, by means of Markov chains, Susceptible-Infected-Recovered (SIR) models (Chen et al., 2015; Dasaklis et al., 2012) and discrete event simulation (Digital twin). 
There is a high possibility of project transfer, since there are many hospitals and health services nationally (as well as in other countries with fewer health resources available) that are currently in a similar situation and do not have the proper instruments to deal with it. Furthermore, in addition to the practical utility of this project for cooperating hospitals, a line of research is opened up that will undoubtedly lead to relevant contributions in the area of operations management and healthcare management.

\subsection{Methodology}

Action research (Avella \& Alfaro, 2014; Erro-Garcés \& Alfaro-Tanco, 2020; Marin-Garcia et al., 2018; Mejia-Villa \& Alfaro-Tanco, 2017) in a framework of recursive optimization-simulation for mathematical modeling based on discrete events (integer linear programming based on scenarios), with a focus on queuing theory and Markov chains (Belanger et al., 2020; Saez-Mas et al., 2018, 2020) will be proposed. We will develop the basis for the models with tools that are accessible to the heads of cooperating health centers or health systems. Discrete event simulators allow variability to be added to the parameters, to show in a more intuitive manner the results and test the impact of scenarios and different strategies.

The model facilitates hospital planning with estimates of the daily number of resources needed and how these compare to the available resources. To achieve this, it can use historic admissions data until the first day being simulated, and after that day, predictions of possible admissions. For the definition of admission prediction scenarios, we will use the peak admissions per day and the time from the start of the outbreak until the peak. The expected patients are clustered according to different shared patterns. The percentage of each group, the mean duration of patient stays in days and the expected phases of evolution will be adjusted to the latest information available.

The research will be carried out in the context of a public health institution (hospital or public health management unit). To do this, it is necessary to have input data and delimit an area of activity, but a randomized sampling process is not required that is generalizable to a population different from the one in the context being examined. The approximation thus seems more like a dimensioned convenience sample for the "theoretical saturation" of the model. We will need historical data (preferably from early March 2020), and cooperation and data collection are anticipated throughout 2020, or until the COVID-19 crisis is believed to have ended.

The geographic area to cover is a medium-sized city and its surrounding metropolitan areas (of less than 1,600,000 inhabitants, $19 \%$ of whom are over age 65 ). The mean temperature during the months of March to June varies between $15{ }^{\circ} \mathrm{C}$ and $23{ }^{\circ} \mathrm{C}$, with a relative humidity of around $64 \%$ (Generalitat Valenciana, 2018).

The healthcare system in the study area is organized into 5 health departments, each of which has 1-2 hospitals responsible for providing care for around 270,000-360,000 citizens. In normal periods, the level of staff on leave is around $20 \%$, of which $40 \%$ is substituted and the duties of the rest are assumed as extra work by the rest of the personnel at the center. It is anticipated that the number of infected healthcare workers would increase this percentage of staff on leave and that substituting them would be more complicated. A total of 2,981 beds are available (it has not been possible to identify how many of these correspond to ICUs). The mean occupancy index during 2018 was around $75 \%$ of the available beds, and the mean stay after admission was 5.6 days (Generalitat Valenciana, 2018).

Hospital doctors are organized into specialties and medical areas of a reasonable size for a normal situation. This organizational method has long-term advantages for the system (in-depth, specific learning; teams of a manageable size, workloads that are easy to calculate, etc.) and for the patient (one face that stays with the patient throughout the entire process, a specialized team that provides support to the doctor). Patients are housed in rooms or wards where the specialties perform their activities, which is known as functional distribution (Arias Aranda \& Minguela Rata, 2018). The logic is to facilitate the work of specialist physicians and nursing teams. The functional division (the closed nature of the specialties) only poses problems when peaks in demand occur (flu epidemics, spring allergies, large accidents, etc.). At those times, the service is saturated, and the doctors affected must deal with the peak. In this case, one ward may be full of patients, while other areas of the hospital are practically empty. These temporary seasonal peaks occur and are followed by stages with a lower work load.

The peak that the Spanish healthcare system is currently facing in its Internal Medicine, Pulmonology and Infectious Diseases specialties is probably not temporary, and it is also not seasonal. It is also reasonable to assume that the work 
in other areas has been reduced (there are fewer work-related and car accidents, fewer heart attacks by people who go out jogging, etc.).

In our research, we will focus only on patients admitted with possible COVID-19 at centers participating in the study, broken down into age ranges ( $<20$ years, 20-64 years and over age 65) (Vall d'Hebron Barcelona Hospital Campus, 2020).

The data that would seem necessary to conduct the simulation are:

Data on the population served by the hospital

1. Total reference population in thousands of inhabitants. Broken down into the following age groups:
a. $<20$ years old
b. 20-64 years old
c. 65 years old or over

2. Total population expanded in anticipation of potential referrals
a. $<20$ years old
b. 20-64 years old
c. 65 years old or over

Hospital resource data (if these data vary as the result of transfers or reinforcements, they will be updated as the changes occur):

1. Number of beds with $100 \%$ dedicated staff, broken down by... (some data may be zero if these are not separate areas at the hospital)
a. Number of beds for pre-diagnosis admissions
b. Number of beds for admissions diagnosed with COVID
c. Number of ICU-RICU beds
d. Number of post-ICU beds
e. Number of post-hospitalization isolation beds
f. Number of fixed mechanical ventilators available
g. Number of portable mechanical ventilators available

2. Staff (staff doctors/residents, nursing staff and hospital attendants) for each area of care (emergency room, pre-diagnosis admissions, admissions diagnosed with COVID-19, RICU, ICU, post-ICU and post-hospitalization isolation)

Forecast admissions to the hospital (provided by sources other than this project, based on the population served and the attack rate of the disease. For example, the initiative by the Spanish Mathematics Committee): evolution of those infected.

Progression of patients in the hospital system (percentages of evolution and mean length of stay):

1. Number of admitted patients per day in relation to COVID-19 at the hospital and number of patients seen/admitted each day in the emergency room, pre-diagnosis, COVID-19 diagnosis, RICU, ICU, post-ICU, posthospitalization isolation

2. Time to develop symptoms and home-based monitoring before hospital triage

3. $\%$ of emergency room walk-ins with respiratory-type symptoms that require admission

4. $\%$ of admissions that are positive or suspected to have COVID-19

$5 . \%$ of positive admissions that evolve satisfactorily until dismissal and duration of the evolution

6. $\%$ of positive admissions that suffer complications and require IMV (duration of the stay with NIMV prior to IMV) and duration of the evolution 
7. $\%$ of patients who require IMV, but for whom intubation is not recommended, $\%$ recovery, $\%$ exitus (transit time until exitus) and duration of the evolution

8. $\%$ of patients who are intubated and have a quick resolution (exitus). Duration of the same

$9 . \%$ of patients who are intubated and recover. Duration of the same

The data provided by the hospital/center/health institution must not permit the direct or indirect identification of the patients referred to. Once the participating center agrees to the consultation of their databases and the procedure to render the data anonymous, the consultation will be performed periodically and a file will be supplied to the research group (via an email sent to the researcher designated for data collection), in order to facilitate the updating of the simulation parameters.

Possible risk of bias exists, due to mainly three reasons; the fact that the characterization of the positive COVID-19 diagnosis may be biased; the reliability and consistency of the data entered in the hospital computer system (which will be our data source); and finally the quick and not always declared evolution of the treatments during the acute phase of the pandemia.

\subsection{Work Plan}

March 2020. Creation of the draft tools based on public data.

April 2020. Approval of the work protocol.

April 2020 - end of the project:

1. Refinement of the model (April 24 - May 15)

2. Obtaining and processing real hospital data (April 24 - May 15)

3. Loading data into the simulator and generating periodic reports with the results (May 15 - end of the project)

4. Reprogramming of the simulators when there are changes in the parameters (1 week)

5. If personnel dedicated to the project is available, hospital personnel can be trained for the piloting of the simulators during periods without noticeable changes in the parameters (4 weeks)

\section{Declaration of Conflicting Interests}

The authors declared no potential conflicts of interest with respect to the research, authorship, and/or publication of this article.

\section{Funding}

The authors received no financial support for the research, authorship, and/or publication of this article.

\section{References}

Åhlström, P. (1998). Sequences in the implementation of lean production. European Management Journal, 16(3), 327334. https://doi.org/10.1016/S0263-2373(98)00009-7

Aijing, L., \& Jin, Y. (2015). Design of the Hospital Integrated Information Management System Based on Cloud Platform. West Indian Medical Journal, 64(5, SI), 521-526. https://doi.org/10.7727/wimj.2016.057

Alzubi, E., Atieh, A. M., Abu Shgair, K., Damiani, J., Sunna, S., \& Madi, A. (2019). Hybrid Integrations of Value Stream Mapping, Theory of Constraints and Simulation: Application to Wooden Furniture Industry. Processes, 7(11). https://doi.org/10.3390/pr7110816

Arias Aranda, D., \& Minguela Rata, B. (2018). Dirección de la producción y operaciones. Decisiones estratégicas. Ediciones Pirámide.

Avella, L., \& Alfaro, J. A. (2014). Spanish University Business Chairs used to increase the deployment of Action Research in Operations Management: A case study and analysis. Action Research, 12(2), 194-208. https://doi.org/10.1177/1476750314528010

Aylward, B., \& Liang, W. (2020). Report of the WHO-China Joint Mission on Coronavirus Disease 2019 (COVID-19). The WHO-China Joint Mission on Coronavirus Disease 2019, 2019(February), 16-24. 
https://www.who.int/docs/default-source/coronaviruse/who-china-joint-mission-on-covid-19-finalreport.pdf

Aytug, H., Lawley, M. A., McKay, K., Mohan, S., \& Uzsoy, R. (2005). Executing production schedules in the face of uncertainties: A review and some future directions. European Journal of Operational Research, 161(1), 86-110. https://doi.org/10.1016/j.ejor.2003.08.027

Bae, K.-H., Jones, M., Evans, G., \& Antimisiaris, D. (2019). Simulation modelling of patient flow and capacity planning for regional long-term care needs: a case study. Health Systems, 8(1), 1-16.

https://doi.org/10.1080/20476965.2017.1405873

Bayou, M. E., \& De Korvin, A. (2008). Measuring the leanness of manufacturing systems-a case study of Ford Motor Company and General Motors. Journal of Engineering and Technology Management, 25(4), 287-304. https://doi.org/10.1016/j.jengtecman.2008.10.003

Bean, D. M., Taylor, P., \& Dobson, R. J. B. (2019). A patient flow simulator for healthcare management education. BMJ Simulation \& Technology Enhanced Learning, 5(1), 49-51. https:/ / doi.org/10.1136/bmjstel-2017-000251

Bedoya-Valencia, L., \& Kirac, E. (2016). Evaluating alternative resource allocation in an emergency department using discrete event simulation. Simulation Transactions of the Society for Modeling and Simulation International, 92(12), 1041-1051. https://doi.org/10.1177/0037549716673150

Belanger, V., Lanzarone, E., Nicoletta, V., Ruiz, A., \& Soriano, P. (2020). A Recursive Simulation-Optimization Framework for the Ambulance Location and Dispatching Problem. European Journal of Operational Research. https://doi.org/10.1016/J.EJOR.2020.03.041

Benton, W. C., \& Shin, H. (1998). Manufacturing planning and control: The evolution of MRP and JIT integration. European Journal of Operational Research, 110(3), 411-440.

Berger, G. (1987). Ten ways MRP can defeat you. APICS Conference Proceedings, APICS.

Bhatraju, P. K., Ghassemieh, B. J., Nichols, M., Kim, R., Jerome, K. R., Nalla, A. K. et al. (2020). Covid-19 in Critically Ill Patients in the Seattle Region - Case Series. The New England Journal of Medicine, 1-11. https://doi.org/10.1056/NEJMoa2004500

Brailsford, S., \& Vissers, J. (2011). OR in healthcare: A European perspective. European Journal of Operational Research, 212(2), 223-234. https:// doi.org/10.1016/j.ejor.2010.10.026

Chase, R. B., Jacobs, F. R., \& Aquilano, N. J. (2004). Operations management for competitive management. International Edition. McGraw Hill Irwin.

Chen, W., Guinet, A., \& Ruiz, A. (2015). Modelling the logistics response to a general infectious disease. In IFACPapersOnLine (Vol. 28, Issue 3). https://doi.org/10.1016/j.ifacol.2015.06.078

Cho, M., Song, M., Yoo, S., \& Reijers, H. A. (2019). An Evidence-Based Decision Support Framework for Clinician Medical Scheduling. IEEE Access, 7, 15239-15249. https://doi.org/10.1109/ACCESS.2019.2894116

Choi, T. Y., Dooley, K. J., \& Rungtusanatham, M. (2001). Supply networks and complex adaptive systems: control versus emergence. Journal of Operations Management, 19(3), 351-366. https://doi.org/10.1016/S02726963(00)00068-1

Cooney, R. (2002). Is "lean" a universal production system? Batch production in the automotive industry. International Journal of Operations \& Production Management, 22(10), 1130-1147. https://doi.org/10.1108/01443570210446342

Dasaklis, T. K., Pappis, C. P., \& Rachaniotis, N. P. (2012). Epidemics control and logistics operations: A review. International Journal of Production Economics, 139(2), 393-410. https://doi.org/10.1016/j.ijpe.2012.05.023

Demir, E., Gunal, M. M., \& Southern, D. (2017). Demand and capacity modelling for acute services using discrete event simulation. Health Systems, 6(1), 33-40. https://doi.org/10.1057/hs.2016.1

Doolen, T. L., \& Hacker, M. E. (2005). A review of lean assessment in organizations: an exploratory study of lean practices by electronics manufacturers. Journal of Manufacturing Systems, 24(1), 55-67.

https://doi.org/10.1016/S0278-6125(05)80007-X 
Eroglu, C., \& Hofer, C. (2011). Lean, leaner, too lean? The inventory-performance link revisited. Journal of Operations Management, 29(4), 356-369. https:// doi.org/10.1016/j.jom.2010.05.002

Erro-Garcés, A., \& Alfaro-Tanco, J. A. (2020). Action Research as a Meta-Methodology in the Management Field. International Journal of Qualitative Methods, 19, 160940692091748. https://doi.org/10.1177/1609406920917489

European center for disease prevention and control. (2020). Coronavirus disease 2019 (COVID-19) pandemic: increased transmission in the EU/EE $A$ and the $U K$ - seventh update. 2019(March).

European Centre for Disease Prevention and Control. (2020). Disease background of COVID-19. https://www.ecdc.europa.eu/en/2019-ncov-background-disease

Ferguson, N. M., Laydon, D., Nedjati-Gilani, G., Imai, N., Ainslie, K., Baguelin, M. et al. (2020). Impact of nonpharmaceutical interventions (NPIs) to reduce COVID-19 mortality and healthcare demand. Imperial.Ac.Uk, March, 3-20. https://doi.org/https://doi.org/10.25561/77482

Fernandes, E. G., Santos, J. da S., \& Sato, H. K. (2020). Outbreak investigation in cargo ship in times of COVID-19 crisis, Port of Santos, Brazil. Revista de Saude Publica, 54. https://doi.org/10.11606/s1518-8787.2020054002461

Forrester, J. W. (1997). Industrial dynamics. Journal of the Operational Research Society, 48(10), 1037-1041. https://doi.org/10.1057/palgrave.jors.2600946

Frazee, T., \& Standridge, C. (2016). Conwip versus POLCA: A comparative analysis in a high-mix, low-volume (HMLV) manufacturing environment with batch processing. Journal of Industrial Engineering and Management, 9(2), 432-449. https://doi.org/10.3926/jiem.1248

Geary, S., Disney, S. M., \& Towill, D. R. (2006). On bullwhip in supply chains - Historical review, present practice and expected future impact. International Journal of Production Economics, 101(1 SPEC. IS), 2-18. https://doi.org/10.1016/j.ijpe.2005.05.009

Generalitat Valenciana. (2018). Memoria de Gestión de la Conselleria de Sanitat Universal i Salut Pública.

Goddard, W. (1982). Kanban versus MRP II-which is best for you. Modern Materials Handling, 37(11), 25-29.

Gonzalez-R, P. L., Framinan, J. M., \& Ruiz-Usano, R. (2010). A multi-objective comparison of dispatching rules in a drum-buffer-rope production control system. International Journal of Computer Integrated Manufacturing, 23(2), 155167. https://doi.org/10.1080/09511920903440362

Gupta, M., \& Andersen, S. (2018). Throughput/inventory dollar-days: TOC-based measures for supply chain collaboration. International Journal of Production Research, 56(13), 4659-4675. https://doi.org/10.1080/00207543.2018.1444805

Gupta, M., \& Snyder, D. (2009). Comparing TOC with MRP and JIT: a literature review. International Journal of Production Research, 47(13), 3705-3739. https://doi.org/10.1080/00207540701636322

Hellewell, J., Abbott, S., Gimma, A., Bosse, N. I., Jarvis, C. I., Russell, T. W. et al.. (2020). Feasibility of controlling COVID-19 outbreaks by isolation of cases and contacts. The Lancet Global Health, 8(4), e488-e496. https://doi.org/10.1016/S2214-109X(20)30074-7

$\mathrm{Hu}, \mathrm{X} ., \mathrm{Barnes}, \mathrm{S} .$, \& Golden, B. (2018). Applying queueing theory to the study of emergency department operations: a survey and a discussion of comparable simulation studies. International Transactions in Operational Research, 25(1, SI), 7-49. https:/ /doi.org/10.1111/itor.12400

Ileri, Y. Y. (2016). Implementation Processes of Hospital Information Management Systems: A Field Study in Turkey. Journal of Information \& Knowledge Management, 15(3). https://doi.org/10.1142/S0219649216500313

Jina, J., Bhattacharya, A. K., \& Walton, A. D. (1997). Applying lean principles for high product variety and low volumes: some issues and propositions. Logistics Information Management, 10(1), 5-13. https://doi.org/10.1108/09576059710159655

Kiourtis, A., Mavrogiorgou, A., Menychtas, A., Maglogiannis, I., \& Kyriazis, D. (2019). Structurally Mapping Healthcare Data to HL7 FHIR through Ontology Alignment. Journal of Medical Systems, 43(3). https://doi.org/10.1007/s10916-019-1183-y 
Kiourtis, A., Nifakos, S., Mavrogiorgou, A., \& Kyriazis, D. (2019). Aggregating the syntactic and semantic similarity of healthcare data towards their transformation to HL7 FHIR through ontology matching. International Journal of Medical Informatics, 132. https:/ / doi.org/10.1016/j.ijmedinf.2019.104002

Lin, J. T., Wang, F. K., \& Lee, W. T. (2004). Capacity-constrained scheduling for a logic IC final test facility. International Journal of Production Research, 42(1), 79-99. https:// doi.org/10.1080/0020754032000123588

Maheut, J., Garcia-sabater, J. P., \& Mula, J. (2012). A Supply Chain Operations Lot-Sizing and Scheduling Model with Alternative Operations. In S. P. Sethi, M. Bogataj, \& L. Ros-McDonnell (Eds.), Industrial Engineering: Innovative Networks (pp. 309-316). Springer-Verlag London Limited. https://doi.org/10.1007/978-1-4471-2321-7

Manninen, K. (2020). Typical progress of covid-19. https://www.flickr.com/photos/187830149@N08/49734417642/

Marin-Garcia, J. A., Garcia-Sabater, J. J., \& Maheut, J. (2018). Protocol: action planning for action research about kaizen in public organizations. The case of higher education. WPOM-Working Papers on Operations Management, 9(1), 1. https://doi.org/10.4995/wpom.v9i1.8990

Marin-Garcia, J. A., Vidal-Carreras, P. I., Garcia Sabater, J. J., \& Escribano-Martinez, J. (2019). Protocol: Value Stream Maping in Healthcare. A systematic literature review. WPOM-Working Papers on Operations Management, 10(2), 36. https://doi.org/10.4995/wpom.v10i2.12297

Martín-barroso, D., Núñez-Serrano, J. A., Turrión, J., \& Velázquez, F. J. (2020). Encajando el puzle: Una estimación rápida del número de infectados por COVID-19 en España a partir de fuentes indirectas. FEDE $A$, dt2020-05. http://documentos.fedea.net/pubs/dt/2020/dt2020-05.pdf

Mejia-Villa, A., \& Alfaro-Tanco, J. A. (2017). Action Research Projects: one step ahead in the researcher-practitioner relationships. WPOM-Working Papers on Operations Management, 8, 191. https://doi.org/10.4995/wpom.v8i0.7660

Miclo, R., Lauras, M., Fontanili, F., Lamothe, J., \& Melnyk, S. A. (2019). Demand Driven MRP: assessment of a new approach to materials management. International Journal of Production Research, 57(1), 166-181. https://doi.org/10.1080/00207543.2018.1464230

Moktadir, M. A., Ali, S. M., Mangla, S. K., Sharmy, T. A., Luthra, S., Mishra, N., \& Garza-Reyes, J. A. (2018). Decision modeling of risks in pharmaceutical supply chains. Industrial Management \& Data Systems, 118(7, SI), 1388-1412. https://doi.org/10.1108/IMDS-10-2017-0465

Molina-Pariente, J. M., Fernandez-Viagas, V., \& Framinan, J. M. (2015). Integrated operating room planning and scheduling problem with assistant surgeon dependent surgery durations. Computers \& Industrial Engineering, 82, 820. https://doi.org/10.1016/j.cie.2015.01.006

Monden, Y. (2011). Toyota production system: an integrated approach to just-in-time. Productivity Press.

Mula, J., Poler, R., \& Garcia-Sabater, J. (2007). Material Requirement Planning with fuzzy constraints and fuzzy coefficients. Fursy Sets and Systems, 158(1), 783-793. https://doi.org/10.1016/j.fss.2006.11.003

National Vital Statistics System. (2020). Provisional Death Counts for Coronavirus Disease (COVID-19). Centers for Disease Control and Prevention. https://www.cdc.gov/nchs/nvss/vsrr/covid19/index.htm https://www.cdc.gov/nchs/nvss/vsrr/covid19/index.htm

Ohno, T. (1988). Toyota production system: beyond large-scale production. crc Press.

Paavola, A. (2020). 256 hospitals furloughing workers in response to COVID-19. Becker's Healthcare Hospital CFO report. https:/ /www.beckershospitalreview.com/finance/49-hospitals-furloughing-workers-in-response-to-covid-19.html

Packowski, J. (2013). Lean supply chain planning: the new supply chain management paradigm for process industries to master today's VUCA world. CRC Press.

Paul, S. A., Reddy, M. C., \& DeFlitch, C. J. (2010). A Systematic Review of Simulation Studies Investigating Emergency Department Overcrowding. Simulation-Transactions of the Society for Modeling Simulation International, 86(89), 559-571. https://doi.org/10.1177/0037549710360912

Pérez-Campdesuñer, R., Pérez-Pravia, M., Sánchez-Rodríguez, A., García-Vidal, G., \& Martínez-Vivar, R. (2017). Application of a methodology based on the theory of constraints in the sector of tourism services. Journal of Industrial Engineering and Management, 10(1), 7-27. https:// doi.org/10.3926/jiem.2089 
Pitt, M., Monks, T., Crowe, S., \& Vasilakis, C. (2016). Systems modelling and simulation in health service design, delivery and decision making. BMJ Quality \& Safety, 25(1), 38-45. https://doi.org/10.1136/bmjqs-2015-004430

Postacchini, L., Ciarapica, F. E., Bevilacqua, M., Mazzuto, G., \& Paciarotti, C. (2016). A way for reducing drug supply chain cost for a hospital district: A case study. Journal of Industrial Engineering and Management, 9(1), $207-230$. https://doi.org/10.3926/jiem.1262

Ruan, Q., Yang, K., Wang, W., Jiang, L., \& Song, J. (2020). Clinical predictors of mortality due to COVID-19 based on an analysis of data of 150 patients from Wuhan, China. Intensive Care Medicine, 1-3. https://doi.org/10.1007/s00134-020-06028-z

Saez-Mas, A., Garcia-Sabater, J. P., Garcia-Sabater, J. J., \& Ruiz, A. (2020). Redesigning the in-plant supply logistics: A case study. Computers \& Industrial Engineering, 143, 106422. https://doi.org/10.1016/j.cie.2020.106422

Saez-Mas, A., Garcia-Sabater, J. P., \& Morant-Llorca, J. (2018). Using 4-layer architecture to simulate product and information flows in manufacturing systems. International Journal of Simulation Modelling, 17(1), 30-41. https://doi.org/10.2507/IJSIMM17(1)408

Safdar, K. A., Emrouznejad, A., \& Dey, P. K. (2016). Assessing the Queuing Process Using Data Envelopment Analysis: an Application in Health Centres. Journal of Medical Systems, 40(1). https://doi.org/10.1007/s10916-0150393-1

Salje, H., Kiem, C. T., Lefrancq, N., Courtejoie, N., Paireau, J., Andronico, A. et al. (2020). Estimating the burden of SARS-CoV-2 in France. HAL, pasteur-02548181. https://hal-pasteur.archives-ouvertes.fr/pasteur-0. https://hal-pasteur.archives-ouvertes.fr/pasteur-02548181

Sanchis, J., \& Martínez, J. (2020). Sanidad desconoce aún el uso que dará a los hospitales de campaña sin terminar. Las Provincias, 16th April. https://www.lasprovincias.es/comunitat/sanidad-des.

https:/ /www.lasprovincias.es/comunitat/sanidad-desconoce-dara-20200415184910-nt.html

Shingo, S., \& Dillon, A. P. (1989). A study of the Toyota production system: From an Industrial Engineering Viempoint. CRC Press.

Sholihah, S. A., Samadhi, T. M. A. A., Cakravastia, A., \& Nur Bahagia, S. (2018). Coordination model in hinterland chain of hub-and-spoke export trade logistics. Journal of Industrial Engineering and Management, 11(4), 776793. https://doi.org/10.3926/jiem.2538

Sodhi, M. S., \& Tang, C. S. (2011). The incremental bullwhip effect of operational deviations in an arborescent supply chain with requirements planning. European Journal of Operational Research, 215(2), 374-382. https://doi.org/10.1016/j.ejor.2011.06.019

Squires, H., Chilcott, J., Akehurst, R., Burr, J., \& Kelly, M. P. (2016). A systematic literature review of the key challenges for developing the structure of public health economic models. International Journal of Public Health, 61(3), 289-298. https://doi.org/10.1007/s00038-015-0775-7

Thürer, M., Land, M. J., Stevenson, M., Fredendall, L. D., \& Godinho Filho, M. (2015). Concerning Workload Control and Order Release: The Pre-Shop Pool Sequencing Decision. Production and Operations Management, 24(7), 1179-1192. https://doi.org/10.1111/poms.12304

Vall d'Hebron Barcelona Hospital Campus. (2020). Pla de contingència de Vall d'Hebron per fer front a l'epidèmia del SARSCoV-2 (pp. 1-53). 17th March.

van Donk, D. P. (2010). Lean for the process industries-dealing with complexity. PL King. Taylor \& Francis.

Verity, R., Okell, L. C., Dorigatti, I., Winskill, P., Whittaker, C., Imai, N. et al. (2020). Estimates of the severity of coronavirus disease 2019: a model-based analysis. The Lancet Infectious Diseases. https:/ / doi.org/10.1016/S14733099(20)30243-7

Vidal-Carreras, P. I., Garcia-Sabater, J. J., Marin-Garcia, J. A., \& Garcia-Sabater, J. P. (2015). Value stream mapping on healthcare. 2015 International Conference on Industrial Engineering and Systems Management (IESM), 272-276. https://doi.org/10.1109/IESM.2015.7380170 
Wanying, C., Alain, G., \& Angel, R. (2016). Modeling the logistics response to a bioterrorist anthrax attack. European Journal of Operational Research, 254(2), 458-471. https://doi.org/10.1016/j.ejor.2016.03.052

Wee, H. M., Budiman, S. D., Su, L. C., Chang, M., \& Chen, R. (2016). Responsible supply chain management - an analysis of Taiwanese gutter oil scandal using the theory of constraint. International Journal of Logistics-Research and applications, 19(5), 380-394. https://doi.org/10.1080/13675567.2015.1090964

Zhang, T., Mcfarlane, K., Vallon, J., Ba, B. S., Yang, L., Xie, J. et al. (2020). A model to estimate bed demand for COVID-19 related hospitalization. Department of Management Science and Engineering, Stanford University School of Engineering, Stanford Graduate School of Business , Stanford, CA Harvard Medical School , Boston , MA In. MedRxiv, 24-28. https://doi.org/10.1101/2020.03.24.20042762

Zhou, F., Yu, T., Du, R., Fan, G., Liu, Y., Liu, Z. et al. (2020). Clinical course and risk factors for mortality of adult inpatients with COVID-19 in Wuhan, China: a retrospective cohort study. The Lancet, 395, 1054-1062.

https://doi.org/10.1016/S0140-6736(20)30566-3

\section{Journal of Industrial Engineering and Management, 2020 (www.jiem.org)}

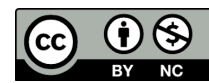

Article's contents are provided on an Attribution-Non Commercial 4.0 Creative commons International License. Readers are allowed to copy, distribute and communicate article's contents, provided the author's and Journal of Industrial Engineering and Management's names are included. It must not be used for commercial purposes. To see the complete license contents, please visit https://creativecommons.org/licenses/by-nc/4.0/. 